\title{
Cerebrovascular disease in pregnancy and puerperium: perspectives from neuroradiologists
}

\author{
Naiwu Wang ${ }^{1 \#}$, Xudong Shen ${ }^{2 \#}$, Gang Zhang ${ }^{3}$, Bo Gao $^{4,5}$, Alexander Lerner ${ }^{6}$ \\ ${ }^{1}$ Department of Radiology, Jinan City People's Hospital, Laiwu, China; ${ }^{2}$ Department of Radiology, Enshi Center Hospital, Enshi, China; \\ ${ }^{3}$ Department of Radiology, Yantai Yuhuangding Hospital, Yantai, China; ${ }^{4}$ Department of Radiology, The Affiliated Hospital of Guizhou Medical \\ University, Guiyang, China; ${ }^{5}$ Key Laboratory of Brain Imaging, Guizhou Medical University, Guiyang, China; ${ }^{6}$ Department of Radiology, Keck \\ School of Medicine, University of Southern California, Los Angeles, CA, USA \\ "These authors contributed equally to this work.
}

Correspondence to: Bo Gao, MD. Department of Radiology, The Affiliated Hospital of Guizhou Medical University, Key Laboratory of Brain Imaging, Guizhou Medical University, Guiyang 550004, China. Email: gygb2004@163.com; Gang Zhang, BSc. Department of Radiology, Yantai Yuhuangding Hospital, Yantai 264000, China. Email: sweetheart2@163.com.

\begin{abstract}
Pregnancy-related cerebrovascular disease is a serious complication of pregnancy and puerperium. The etiology and pathological mechanisms of cerebrovascular disease are complex, involving changes in the cardiovascular, endocrine, and immune systems. Vascular risk factors during pregnancy and puerperium may cause vasospasm and endothelial cell damage leading to cerebral ischemia, hemorrhage, posterior reversible encephalopathy syndrome (PRES), and reversible cerebral vasoconstriction syndrome. Arterial or venous obstruction may damage the blood-brain barrier (BBB) and impede venous return, resulting in cerebral edema, hemorrhage, and intracranial hypertension. Pregnancy with hypercoagulability may threaten the lives of both the mother and the developing fetus. With improvements in stroke treatment during pregnancy and puerperium, neuroradiologists have gained new insights into this problem. This article reviews the pathogenesis, imaging findings, and risk factors of stroke during pregnancy and puerperium, focusing on imaging diagnosis and prognostic assessment.
\end{abstract}

Keywords: Cerebrovascular circulation; stroke; imaging; pregnancy; puerperium

Submitted Jul 05, 2020. Accepted for publication Oct 18, 2020.

doi: $10.21037 /$ qims-20-830

View this article at: http://dx.doi.org/10.21037/qims-20-830

\section{Introduction}

A pregnancy-related stroke usually refers to a stroke occurring during pregnancy and up to 6 weeks postpartum, although some thrombotic events may extend to 12 weeks postpartum (1). In a large sample study, 16,694 (0.045\%) of $37,360,772$ pregnancy-related hospitalizations involved acute strokes. A total of 703 patients with acute stroke/transient ischemic attack (TIA) died during the hospital stay. In-hospital mortality was almost 385 times higher among pregnant women with acute stroke/TIA compared to those who had not suffered a stroke. Mortality was increased among patients with acute stroke/TIA in the following cases: age $\geq 40$ years, black and Asian races, hemorrhagic stroke (compared with ischemic stroke), anemia, heart failure, cardiomyopathy, atrial fibrillation, hypertension, preeclampsia/eclampsia, gestational diabetes, and cesarean delivery (2). Risk factors for stroke during pregnancy and the puerperal period include gestational hypertension, HELLP syndrome (characterized by hemolysis, elevated liver enzymes, and thrombocytopenia), frequent vomiting, and changes in hemolysis and the prethrombotic state in late pregnancy and the postpartum period (3). Also, multiparity, older-age pregnancy, multiple pregnancies, diabetes, and water-electrolyte imbalance may 
Table 1 Vascular risk factors in pregnancy

\begin{tabular}{|c|c|c|}
\hline Hypercoagulable state & Blood stasis & Endothelial injury \\
\hline $\begin{array}{l}\text { Decreased activity of antithrombin (AT) III, protein S, and } \\
\text { protein C }\end{array}$ & $\begin{array}{l}\text { Increased blood volume, slow } \\
\text { venous return }\end{array}$ & $\begin{array}{l}\text { Drug-induced endothelial cell } \\
\text { dysfunction }\end{array}$ \\
\hline $\begin{array}{l}\text { Increased levels of plasminogen activator inhibitors } 1 \text { and } \\
2 \text { (PAI-1, PAI-2) }\end{array}$ & $\begin{array}{l}\text { Long-term bed rest and surgical } \\
\text { immobilization }\end{array}$ & Infection \\
\hline
\end{tabular}

increase stroke incidence $(4,5)$.

Acute cerebrovascular complications associated with pregnancy represent a serious problem that may lead to maternal and fetal death. Also, these complications' longterm outcomes can negatively impact the rest of a woman's life (6). Rapid brain imaging can help diagnose acute stroke, identify the cause of stroke, and determine the optimal treatment strategies.

\section{Cerebrovascular risk factors}

Pregnancy triggers a hypercoagulable state. Normally, pregnancy can cause an increase in fibrinogen in the blood, thereby further increasing the activity of factors VII, VIII, X, as well as von Willebrand factor in the blood, while also inhibiting the activities of antithrombin (AT) III, protein S, and protein C (7). Additionally, the levels of plasminogen activator inhibitor type 1 (PAI-1) and placenta-derived plasminogen activator inhibitor type 2 (PAI-2) increase significantly (8). Such changes often occur in the early stages of pregnancy and extend up to 12 weeks postpartum to prevent excessive bleeding caused by postpartum birth canal injury (9). In order to adapt to the growth and development of the fetus during pregnancy, the blood volume increases through the action of estrogen, progesterone, and prolactin (10). During pregnancy, progesterone is constantly increasing, causing blood vessels to dilate and venous return to diminish. Some studies $(11,12)$ have shown that when postpartum progesterone levels are rapidly reduced, cerebral vasoconstriction can cause cerebral ischemia, with severe cases resulting in ischemic stroke, representing one of the important reasons for the high incidence of postpartum stroke (Table 1).

\section{Cerebrovascular risk factors during pregnancy}

The physiological environment during pregnancy will lead to different structural changes of the cerebrovascular system. Blood volume, stroke volume, and cardiac output increase during pregnancy, peaking at 25-30 weeks, and increasing further before and after delivery (13). Total peripheral vascular resistance markedly decreases to accommodate greater plasma volume (14). Excessive blood pressure and high blood volume may lead to arterial contraction and result in ischemia. Decreased placental perfusion leads to excessive placental factors, destroying the blood-brain barrier (BBB) and cerebral edema (15). It has also been shown that non-gestational hypertension may lead to an increased vascular wall thickness and smaller lumen. When preeclampsia occurs in pregnancy, the vascular wall does not thicken, which may lead to impaired cerebral blood flow (CBF) autoregulation, BBB disruption, brain edema, and long-term postpartum neurological complications (16). Preeclampsia is an important disorder that affects vascular endothelial function (15). Hypercoagulability, infection, injuries sustained during delivery, and genetic factors may also cause endothelial damage. Endothelial injury can cause local coagulation and fibrinolysis abnormalities, leading to thrombosis and cerebral ischemia. Cerebral ischemia may destroy small arteries and lead to bleeding events.

The pregnancy process may be associated with other vascular risks. In a study of 1,005 pregnant women, Skilton et al. (17) found that pregnancy can reduce highdensity lipoprotein and apolipoproteins A and B, causing atherosclerosis and increasing the risk of stroke. Pregnant women should be alert to cerebrovascular risks when they have difficulty breathing, sudden severe headaches, and sudden changes in nervous system symptoms (including changes in consciousness, speech, muscle strength, vision, balance, or sensation on one side of the body) (18). Timely imaging evaluation is an effective means of detecting complications involving the central nervous system. 


\section{Ischemic stroke}

Pregnancy and puerperium are associated with a higher risk of thromboembolism. Severe hypertension [systolic blood pressure $\geq 160 \mathrm{mmHg}$, or diastolic blood pressure $\geq 110 \mathrm{mmHg}$ ] is a predisposing factor for ischemic stroke in pregnant women (19). Furthermore, a previous study reported that $47 \%$ of ischemic stroke occurred in patients with eclampsia and preeclampsia (20). The pathogenesis of ischemic stroke is primarily due to the high agglutination of the blood during pregnancy and various risk factors causing cerebral arterial spasm and endothelial cell destruction, owing to the obstruction of organ blood supply. Patients with right-to-left intracardiac shunt or patent foramen ovale may experience air and venous emboli entering the nervous system through intracardiac physiological channels. For example, air entering the cerebral circulation may lead to various neurologic signs and symptoms (21).

Emergency treatment of stroke during pregnancy and puerperium is similar to non-gestational stroke, and rapid and accurate diagnosis is essential. Recent studies have shown that intravenous thrombolysis with recombinant tissue plasminogen activator (rt-PA) and intravascular mechanical thrombectomy are the most effective treatments for acute stroke. However, for pregnant women, who represent a special group, only a small number of cases show that intravascular mechanical thrombectomy has advantages with no significant side effects. Further research is needed to determine whether this method is sufficiently safe for pregnant women with stroke (22-24). Case reports have shown that rt-PAs can increase bleeding after intravenous thrombolysis, and the risk of bleeding after cesarean section is also more significant (25).

Imaging is the main diagnostic tool for pregnancyrelated stroke. Stroke should be suspected in patients with neurological symptoms, especially sudden progressive headache during pregnancy and perinatal periods, accompanied by focal neurological signs and symptoms, including abnormal limb movements, convulsions, and papilledema. Timely computed tomography (CT), magnetic resonance imaging (MRI), and angiography examinations should be obtained. Previous studies have shown that MRI does not affect the fetus, however, contrast agents containing gadolinium are associated with an increase in stillbirth and neonatal mortality (26). CT of the head has less influence on the fetus, however this exam utilizes ionizing radiation and should be considered only when necessary (such as due to poor availability of MRI) to avoid delays in diagnosis and treatment (22). There is no evidence that CT contrast agents have any known hazards to humans or animals, so breast-feeding mothers undergoing enhanced CT examinations do not pose a risk to infants (22). The imaging findings of acute stroke and ischemic syndrome remain essentially the same regardless of whether the patient is pregnant or not. The radiological diagnosis of acute ischemic stroke relies heavily on diffusion weighted imaging (DWI), which may indicate a restricted diffusion of ischemic brain tissue in the acute phase of stroke (27) (Figure 1). Perfusion CT or contrast-enhanced MRI are usually avoided during pregnancy to assess ischemic penumbra, however such routine examinations can be performed in the event of postpartum stroke (27). CT detects only a few cases of ischemic infarction with density changes 6 hours after vascular occlusion. However, most of these cases are still not evident after 24 hours on CT. The detection rate is significantly increased only 48 hours after onset, showing low density lesions in the cerebral cortex or subcortex.

\section{Hemorrhagic stroke}

The vascular risk factors during pregnancy are related to hormone-driven changes in the maternal environment balance. Progesterone can promote vascular connective tissue changes, and the reduction of muscle wall collagen and elastin can lead to the loss of vasodilatation (28). By the end of the second trimester, cardiac output increases, and blood volume and arterial pressure gradually increase (13). Increased arterial pressure and induced births elevate the risk of intracranial hemorrhage. During pregnancy arteriovenous malformations (AVMs) (Figure 2), cavernous hemangiomas and intracranial aneurysms are more likely to hemorrhage. Jaigobin et al. (29) retrospectively analyzed 50,700 pregnant women in Toronto, Canada. Of the patients with cerebral hemorrhage, seven were cases of subarachnoid hemorrhage and six were cases of intraparenchymal hemorrhage. There were three cases of aneurysm rupture and five cases of AVMinduced bleeding. Cerebral hemorrhage secondary to an aneurysm may occur in the early, middle, and late stages of pregnancy, and cerebral hemorrhage secondary to AVM occurs after the early pregnancy and during the puerperium. Dias et al. (30) reported that of the 154 cases associated with aneurysms or AVM, $92 \%$ of bleeding occurred during pregnancy and $8 \%$ occurred during the puerperium. Furthermore, an analysis of risk factors for pregnancyrelated cerebrovascular disease with large control samples has shown that several days before and after childbirth are 

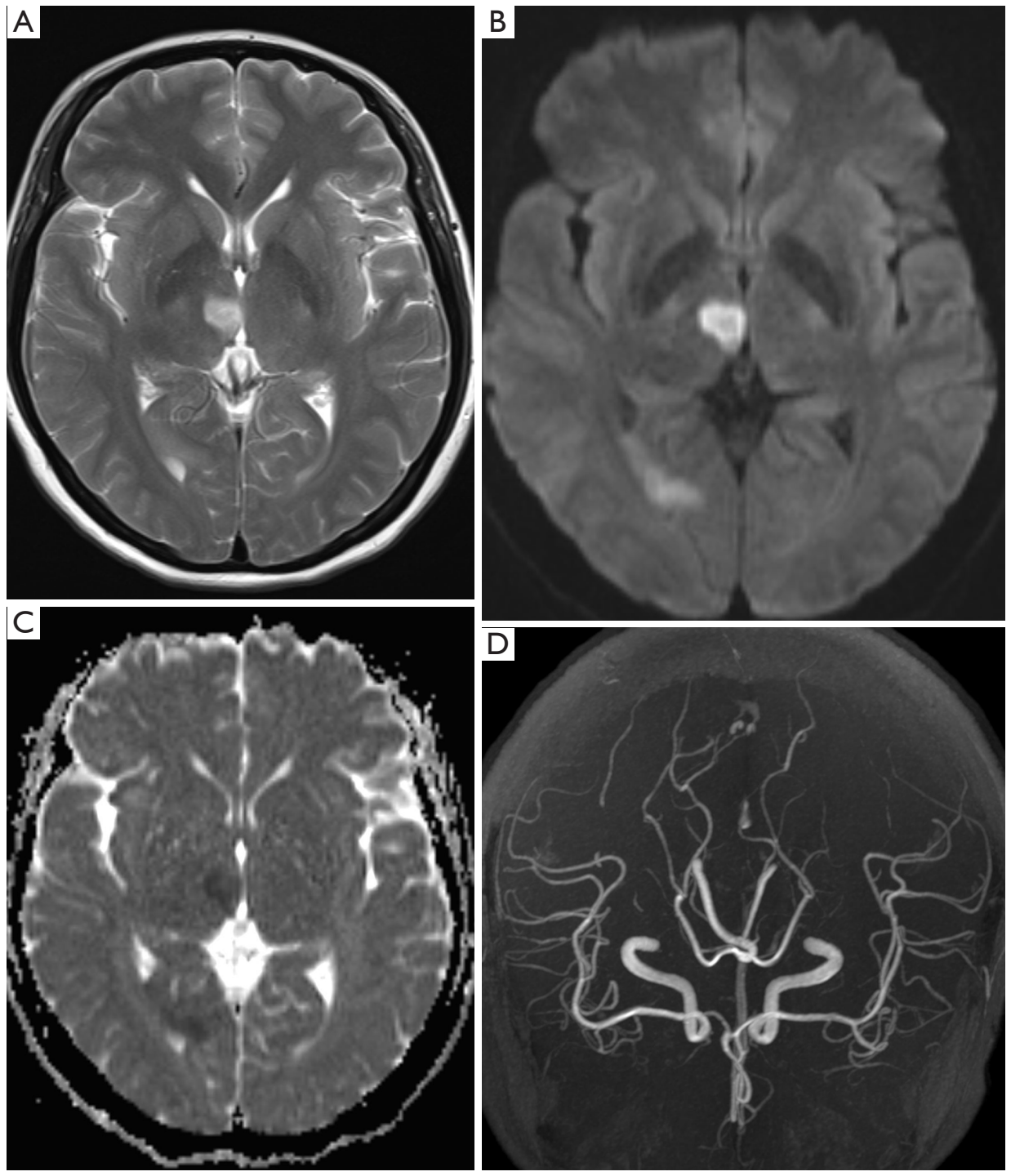

Figure 1 A 20-year-old woman, 34 weeks pregnant, presenting with headaches, dizziness, and progressive left-side weakness. T2-weighted image (T2WI) reveals areas of hyperintensity in the right basal ganglia and occipital periventricular region (A), with corresponding hyperintensity on diffusion weighted imaging (DWI) (B) and diffusion restriction evident on apparent diffusion coefficient (ADC) map (C) suggestive of acute cerebral infarction in these areas. Magnetic resonance angiography (MRA) (D) shows normal cerebral vessels.

high-risk periods for hemorrhage (31).

The predominant cause of intracranial hemorrhage during pregnancy and puerperium is preeclampsia/ eclampsia, with AVM rupture being the second most common (32). The rupture of intracranial aneurysms is the prevailing cause of subarachnoid hemorrhage during pregnancy $(33,34)$. Owing to the hypercoagulable state, birth injuries and infections may lead to thrombosis. When a left-to-right intracardial shunt is present, a thrombus from the systemic circulation or left heart thrombus may embolize to the central nervous system (35). In pregnant patients with cerebral infarction, revascularization in the ischemic area may also lead to secondary bleeding in the infarcted area (Figure 3). Non-contrast-enhanced CT can detect acute intracranial hemorrhage with a sensitivity of greater than $90 \%$ (36), reveal the location of the bleeding, the size of the hemorrhage, and the mass effect on brain tissue, and herniations. After diagnosis of intracranial hemorrhage, magnetic resonance angiography (MRA), computed tomographic angiography (CTA), or digital 

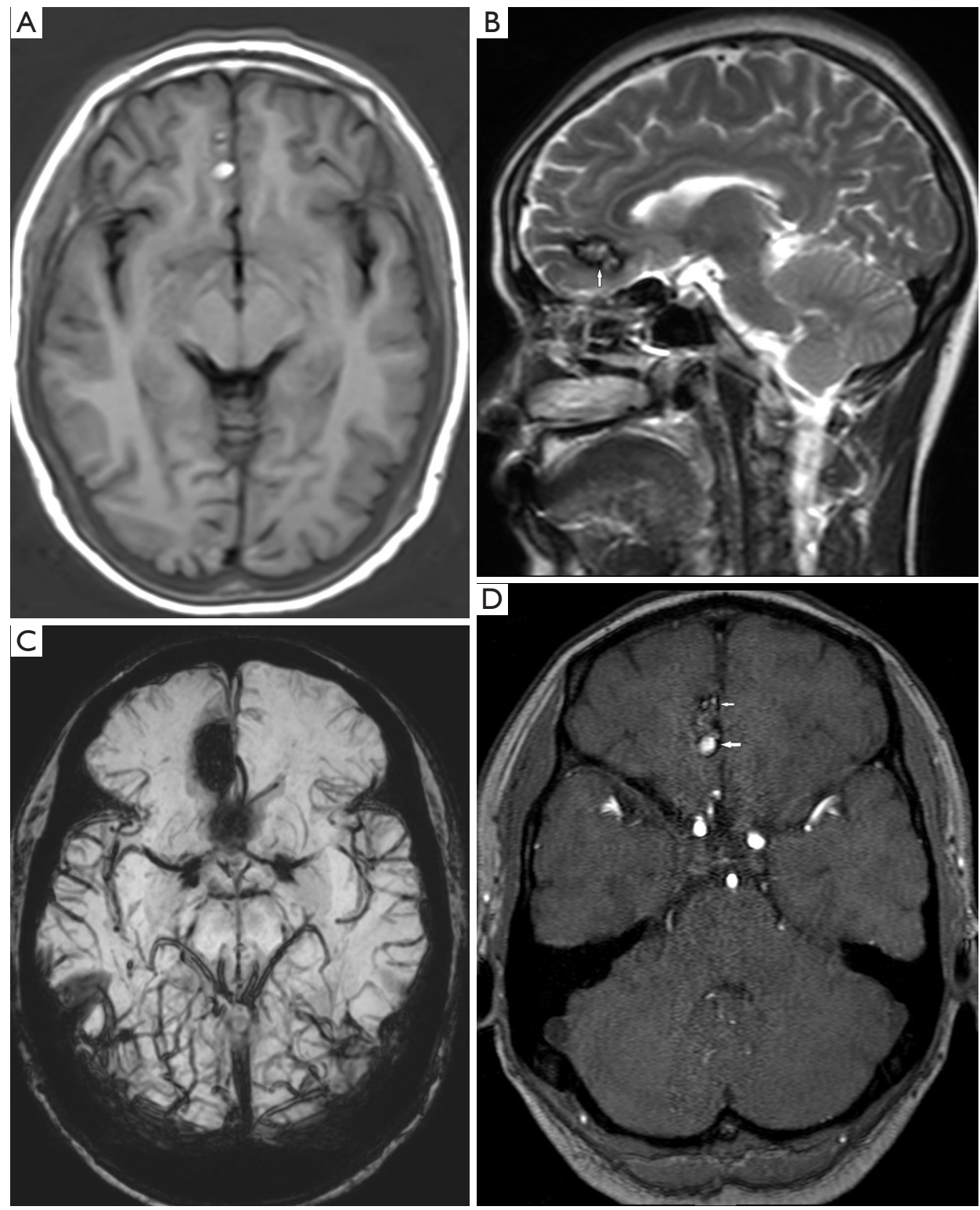

Figure 2 A 25-year-old woman presenting persistent headache and dizziness at 37 weeks gestation. T1-weighted images (T1WI) (A) shows hyperintensities in the right frontal lobe with a hypointense ring around the lesion on sagittal T2-weighted image (T2WI) (B, black arrow), and susceptibility weighted images (SWI) (C) demonstrate susceptibility artifact consistent with chronic hemorrhage. Source image of magnetic resonance angiography (MRA) (D) demonstrates presence of underlying arteriovenous malformation (AVM) (white arrow).

subtraction angiography (DSA) can be used to examine the cause of bleeding. CT scans may not detect AVM, however calcifications might suggest this diagnosis in some patients. CTA can show draining veins, feeding arteries, and nidus of the AVM. DSA is the gold standard for diagnosis of AVM. Aneurysm on angiography is visualized as a saccular outpouching that protrudes from the side of the artery. The shape may be round, oval, or irregular. Non-contrast- enhanced CT may demonstrate a slightly higher density of the aneurysm lumen and calcifications, and MRI may show low or no signal on T1-weighted images (T1WIs) and T2weighted images (T2WIs) due to flow void. Post-contrast scans show arterial phase avid enhancement. Additionally, pulsation artifacts may be present in phase encoding direction most prominently on T2-Fluid-Attenuated Inversion Recovery (FLAIR) images. 

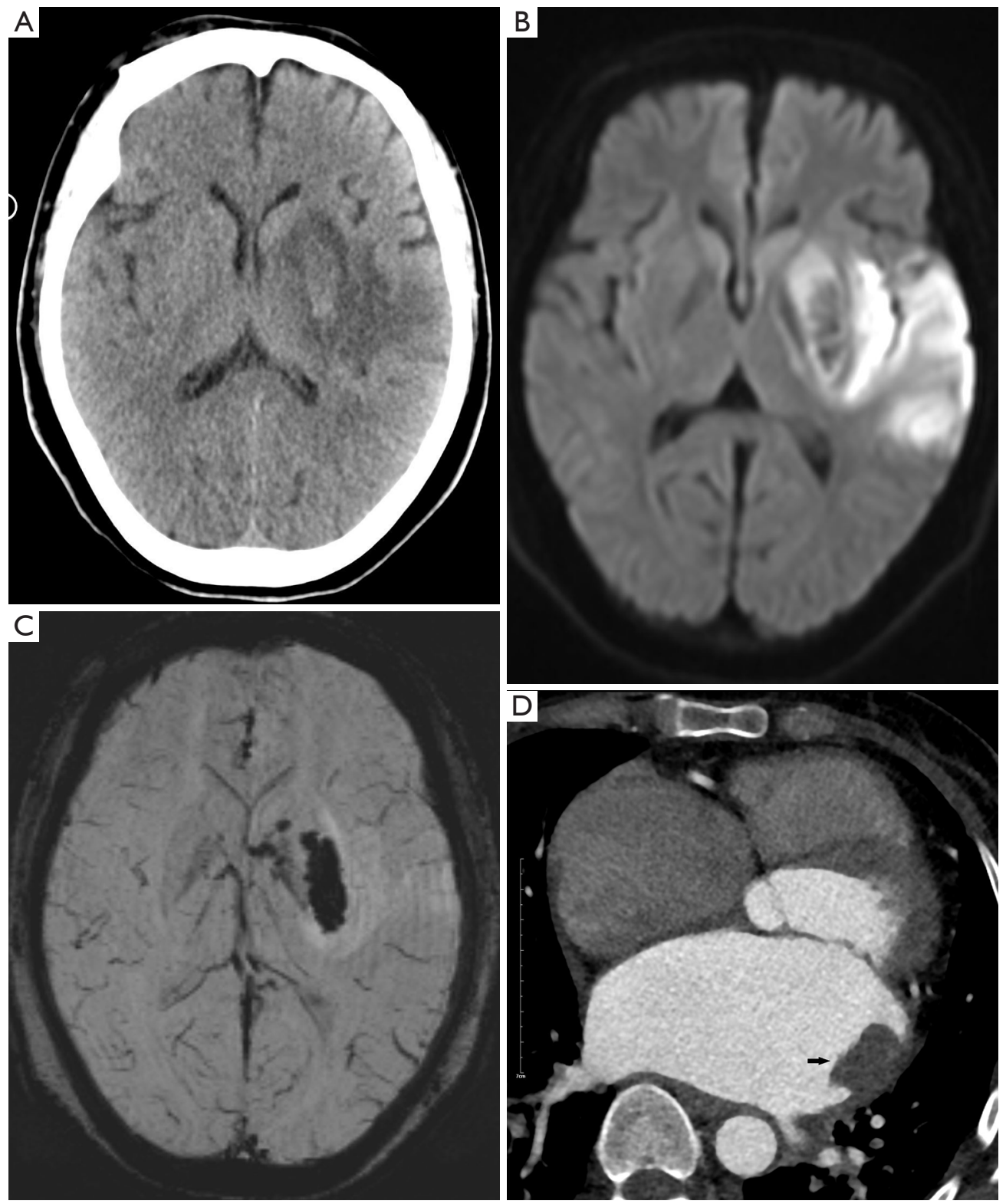

Figure 3 A 28-year-old woman with a history of cardiac insufficiency suddenly developed aphasia and weakness of right limbs 4 days after cesarean section. CT (A) shows a small area of mild high-attenuation in the left basal ganglia with a large area of low-attenuation. Diffusion weighted imaging (DWI) (B) shows slight hypo-intensity in the left basal ganglia and a large hyperintensity area in middle cerebral arteries (MCA) territory suggestive of cerebral infarction. Susceptibility weighted images (SWI) (C) shows marked hypo-intensity consistent with hemorrhage complicating ischemic infarction. Contrast enhanced CT (D) shows low-attenuation thrombosis in the left atrium (black arrow), likely representing the source of infarction from cardiac emboli.

\section{Cerebral venous thrombosis (CVT)}

CVT accounts for approximately $0.5-1.0 \%$ of all intracranial thromboses cases, but in younger patients, the incidence is as high as $5 \%$ of all strokes $(37,38)$. Women of childbearing age are at a higher risk, and about $70 \%$ of CVT occurs in this age group $(39,40)$. The pathogenesis and pathophysiology of pregnancy-related CVT has not yet been fully elucidated, although it is likely related to factors including the hypercoagulable state, blood stasis, and blood vessel wall injury 
(41). Venous sinus thrombosis can obstruct cerebrospinal fluid reflux, decreased $\mathrm{CBF}$ and cerebral perfusion pressure, and impaired BBB (42). Headache is the most common symptom of CVT, with $40 \%$ of patients experiencing epileptic seizures. Up to $76 \%$ of perinatal patients with CVT experience seizures (43). The clinical symptoms of pregnancy-related CVT are predominantly manifested as intracranial hypertension, focal brain tissue damage, seizures and other symptoms (44). In the presence of the symptoms above during pregnancy, CVT's possibility should be considered, and relevant imaging studies should be performed.

Venous infarction is often peripheral, does not conform to the arterial territory, and may involve bilateral deep brain structures. When venous thrombosis occurs, the outflow tract obstruction causes vasodilation. If the collateral drainage is insufficient, the venous pressure may overcome the arterial perfusion pressure, leading to infarction (45) (Figure 4). MRI is often the preferred method of assessing suspected CVT during pregnancy. Magnetic resonance venography (MRV) is the main method for diagnosing CVT, and can show venous sinus filling defects and collateral vein dilatation (42) (Figure 4). In the case of venous thrombosis during the puerperium, gadoliniumbased contrast should also be used and may reveal a lack of contrast enhancement in the thrombosed sinus (46). On gradient-echo and susceptibility weighted images (SWI), the thrombus appears as mostly hypointense for all acute, subacute, and chronic thrombus phases (47).

However, there are pitfalls in the diagnosis of venous sinus thrombosis. Acute thrombi may appear as isointense to the brain parenchyma on T1WI, and hypointense on T2WI. These imaging features simulate a normal flow void (Figure 4) that could be missed by the interpreting neuroradiologist (48). A CT venogram (CTV) is a sophisticated tool for quickly assessing patients with suspected venous thrombosis. CTV can directly show venous sinus thrombosis, manifested as a venous sinusfilling defect, and is more sensitive for detecting thrombi in smaller venous sinuses and partial venous thrombosis (49).

\section{Posterior reversible encephalopathy syndrome (PRES)}

PRES is a clinical syndrome characterized by sudden headache, convulsions, visual disturbances, and other neurological symptoms (50). PRES usually occurs in middle to late pregnancy stages, and the symptoms develop rapidly in 12 to 48 hours (51). There is some controversy about the pathogenesis of PRES. The currently accepted hypothesis is the cerebrovascular autoregulation collapse theory and the capillary endothelial injury theory. Studies have shown that when a normal person's mean arterial pressure fluctuates within a range of $60-150 \mathrm{mmHg}$, the $\mathrm{CBF}$ remains relatively stable through the cerebral arterial autoregulation mechanism (52). However, when the blood volume and blood pressure in pregnancy exceed the automatic regulation mechanism's upper limit, cerebral blood vessels become passively dilated and the cerebral perfusion pressure rises. Thus, liquid macromolecules and even red blood cells penetrate the brain parenchyma through the BBB. Also, because the sympathetic nerve fibers in the vertebral and basilar artery wall are less distributed than the internal carotid artery, the congenital deficiency of this sympatheticadrenergic innervation makes the posterior circulation vessels more prone to dilation. So, vasogenic cerebral edema is more likely to occur in the brain's posterior part (53).

PRES lesions mainly involve bilaterally symmetrical white matter in the posterior part of the brain, including the cortex, brain stem, cerebellum, basal ganglia, corpus callosum, and even the spinal cord. The parietal and occipital lobes are involved in almost all cases (94-98\%), and involvement of the frontal and temporal lobes is also common (77-79\% and $64-68 \%$, respectively) $(52,54,55)$. PRES lesions often show iso-intensity or low signal intensity on T1WI, while on T2WI and FLAIR, they demonstrate high signal intensity. On DWI, the lesions are usually hypointense or isointense and the apparent diffusion coefficient (ADC) map usually demonstrates corresponding high values (Figure 5), which is typical for vasogenic edema (56). While DWI generally shows elevated as opposed to restricted diffusion, reversible restrictive diffusion has also been reported in some cases, suggesting that not all regions with restricted diffusion represent permanent infarction (57). In severe cases, PRES may lead to irreversible parenchymal damage and cerebral ischemic necrosis due to persistent edema or vascular rupture secondary to endothelial damage (58). Previous literature reports that the probability of cerebral hemorrhage in PRES is 5-19.4\% (59). Thus, PRES should not be considered as a completely benign and reversible state.

\section{Reversible cerebral vasoconstriction syndrome (RCVS)}

RCVS is a rare syndrome characterized by recurrent 

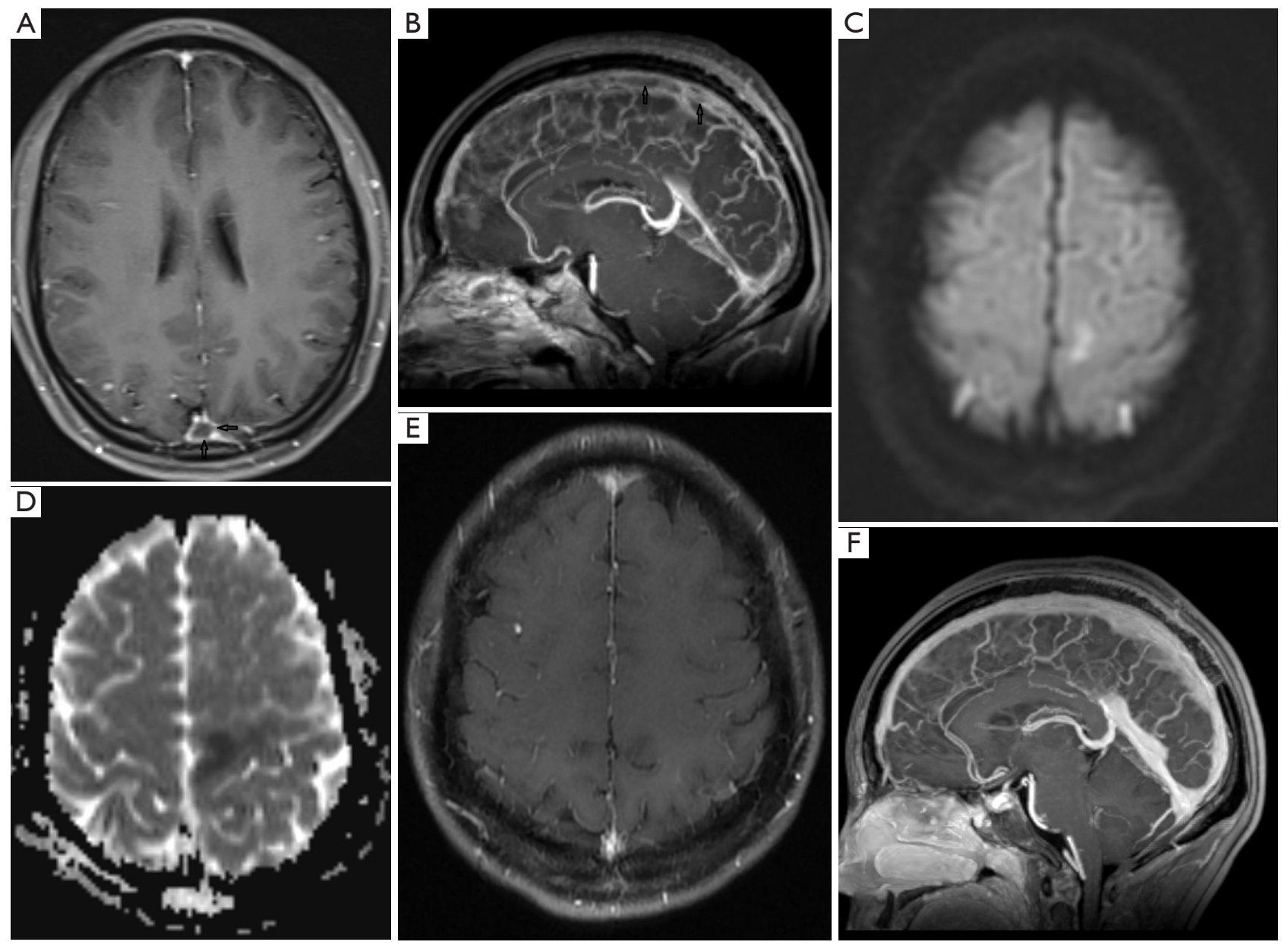

Figure 4 A 25-year-old woman with history of preeclampsia presenting with headaches at 1 week postpartum. Post-contrast T1-weighted images (T1WI) and sagittal reformat maximum intensity projection (MIP) (A,B) show extensive filling defects in the superior sagittal sinus (arrow); diffusion weighted imaging (DWI) (C) and apparent diffusion coefficient (ADC) map (D) demonstrate multiple focal infarcts in the bilateral cerebral cortex. Post-contrast T1WI and reformat MIP (E,F) show thrombus recanalization after active treatment.

severe headache (typically sudden thunder-like headaches) and multiple reversible contractions of cerebral arteries (60). Studies suggest that RCVS in the postpartum period may be associated with elevated levels of pro- and anti-angiogenic factors or secondary to eclampsia (61). Complications of RCVS include PRES, ischemic cerebral infarction, cerebral hemorrhage, cerebral edema, subarachnoid hemorrhage, carotid dissection, and even death $(62,63)$. Vasospasm usually resolves within 1-3 months after onset (64). The purpose of imaging examination of RCVS patients is to show cerebral vasoconstriction, confirm the diagnosis, establish the prognosis, and identify any potential complications (65). Early diagnosis and timely treatment can help avoid serious irreversible neurological deficits.

MRI may show cerebral parenchymal lesions caused by RCVS, such as watershed cerebral infarction, cerebral hemorrhage, subarachnoid hemorrhage, and PRES lesions (66). Patients with RCVS may have hyperintense vessels within sulci on T2-FLAIR images, representing the slowing of blood flow in the cortical and pial vessels. This finding suggests severe cerebral vasoconstriction, and the risk of cerebral infarction and PRES is greatly increased (67). DSA examination is the gold standard for diagnosing RCVS. Typical vascular changes are characterized by moderate vascular segmental and multifocal stenosis (string of beads) in the anterior and posterior cerebral circulation, usually returning to normal 4 to 12 weeks after onset 

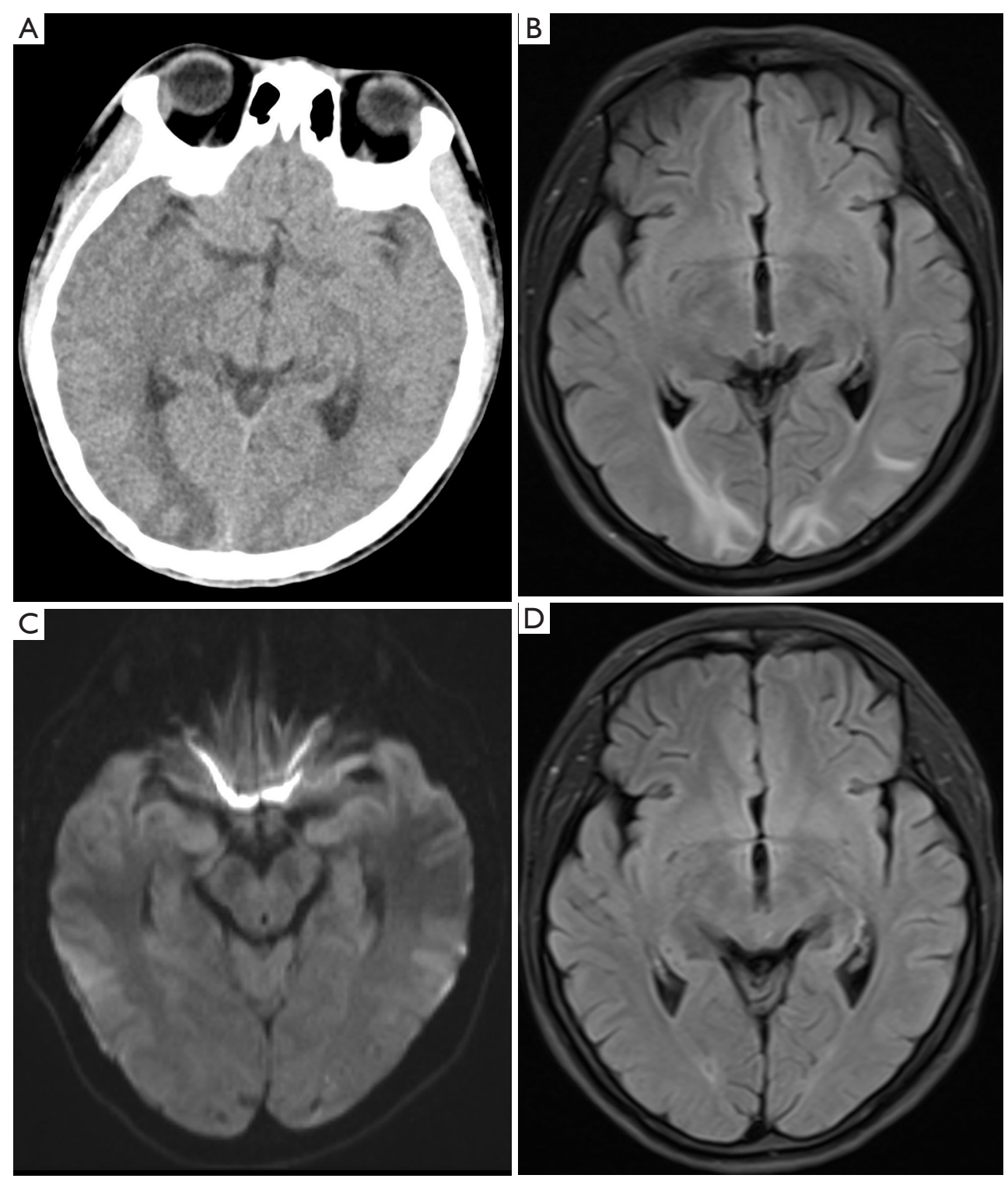

Figure 5 A 21-year-old woman with history of eclampsia presenting with headaches and convulsions. CT (A) shows low-attenuation in the subcortical white matter of the bilateral parietal and occipital lobes. Magnetic resonance imaging (MRI) (B,C) show hyperintensities on T2Fluid-Attenuated Inversion Recovery (FLAIR) and iso-intensity on diffusion weighted imaging (DWI) (D). The lesions resolve after active treatment (D).

$(61,68,69)$. RCVS and PRES often occur simultaneously, and it is reported that $9-38 \%$ of patients with RCVS have concomitant PRES. More than $85 \%$ of PRES patients may exhibit cerebral vasoconstriction similar to RCVS when examined by DSA (68). RCVS imaging findings are similar to the central nervous system's primary angiitis, and both diagnoses should be considered. One study (70) found that vessel wall imaging (VWI) is an important auxiliary tool for identifying intracranial vascular lesions. The most common manifestation of vasculitis on contrast-enhanced VWI is diffuse, uniform annular enhancement of the vessel wall, while RCVS is characterized by mild thickening of the vessel wall, often without enhancement. The combination of non-contrast-enhanced T1WI and T2WI and contrastenhanced VWI would improve sensitivity and specificity of the diagnosis. 


\section{Cerebrovascular accident risk factor management}

Pregnant patients and those in the puerperium period exhibit major physiological differences compared to nonpregnant individuals. The cardiovascular and endocrine systems change during pregnancy, and thus, cardiovascular parameters of non-pregnant people cannot be applied for pregnant women. However, there are no specific parameters for pregnant women. Physicians should exercise their clinical judgment to determine whether the abnormal index reported in a pregnant patient represents true pathological changes, and cannot simply rely on normal reference values as the sole criterion for judgment. Comprehensive analysis of the changes from baseline, medical history, and clinical symptoms at gestational ages should be used to determine if a pregnant patient is at high risk for vascular complications. This analysis will help to optimize the clinical management of these patients.

Whether it is the regulation of the circulatory system by hormones during pregnancy or changes in blood volume caused by variations in plasma protein, the blood pressure, D-dimer, and hematocrit represent objective reflections of the patient's physical state. The "prethrombotic state" caused by poor maternal diet, stress, and decreased exercise cannot be ignored. For high-risk pregnant women with a history of spontaneous abortion, obesity, chronic hypertension, kidney disease, and diabetes, clinicians should be vigilant and provide high-level careful monitoring and management of the cardiovascular system during pregnancy. Simultaneously, women with a history of pregnancy comorbidities should also be screened for thrombotic disorders (71). It is necessary to prevent and cure anemia, thrombocytopenia, and hypoproteinemia during pregnancy and prevent hypercoagulability.

\section{Emergency diagnosis algorithm}

Rapid and accurate diagnosis is essential to ensure the best prognosis and outcome for mothers and infants. Therefore, medical staff education in emergency and obstetrics departments is essential to familiarize them with the neurological signs and symptoms of acute stroke and facilitate rapid diagnosis. It is also necessary to identify stroke types; fatal strokes are mostly caused by bleeding (72). Rapid brain imaging can help diagnose acute stroke, clarify the cause of stroke, and determine treatment options. In recent years, with the application of novel magnetic resonance technologies, some of these new technologies can evaluate the patient's condition and predict prognosis $(73,74)$.

Furthermore, attention should be paid to identify diseases mimicking acute stroke. All pregnant women with severe headaches should be screened. If the cause of headaches cannot be determined, a lumbar puncture cerebrospinal fluid examination should be performed to identify the headache's cause promptly.

\section{Conclusions}

Pregnancy is a unique physiological process in women of childbearing age. The etiological and pathophysiological mechanisms of pregnancy-related stroke are complex. Medical staff in the radiology department should be familiar with the neurological signs and symptoms of acute stroke in such patients and quickly assess for this disorder. Rapid brain imaging studies are critical for the timely diagnosis of acute stroke, identifying the cause of stroke, and selecting optimal treatment strategies.

\section{Acknowledgments}

Funding: This study was funded by the National Natural Science Foundation of China (Grant No. 81871333); Guizhou Province Science and Technology Infrastructure Project (No. [2020]4Y-159); Guiyang science and technology project (No. 2020-10-3); Innovation group project of Guizhou Province Educational Commission (Qian Jiao He KY[2021]017); Key Laboratory Construction Project of Guizhou Medical University.

\section{Footnote}

Conflicts of Interest: All authors have completed the ICMJE uniform disclosure form (available at http://dx.doi. org/10.21037/qims-20-830). BG serves as an unpaid editorial board member of Quantitative Imaging in Medicine and Surgery. The other authors have no conflicts of interest to declare.

Open Access Statement: This is an Open Access article distributed in accordance with the Creative Commons Attribution-NonCommercial-NoDerivs 4.0 International License (CC BY-NC-ND 4.0), which permits the noncommercial replication and distribution of the article with the strict proviso that no changes or edits are made and the original work is properly cited (including links to both the 
formal publication through the relevant DOI and the license). See: https://creativecommons.org/licenses/by-nc-nd/4.0/.

\section{References}

1. Bushnell C, Mccullough L. Stroke Prevention in Women: Synopsis of the 2014 American Heart Association/ American Stroke Association Guideline. Ann Intern Med 2014;160:853.

2. Elgendy IY, Gad MM, Mahmoud AN, Keeley EC, Pepine CJ. Acute Stroke During Pregnancy and Puerperium. J Am Coll Cardiol 2020;75:180-90.

3. Leffert LR, Clancy CR, Bateman BT, Bryant AS, Kuklina EV. Hypertensive Disorders and Pregnancy-related Stroke. Obstet Gynecol 2015;125:124-31.

4. Maino A, Siegerink B, Algra A, Martinelli I, Peyvandi F, Rosendaal FR. Pregnancy loss and risk of ischaemic stroke and myocardial infarction. Br J Haematol 2016;174:302-9.

5. Too G, Wen T, Boehme AK, Miller EC, Leffert LR, Attenello FJ, Mack WJ, D'Alton ME, Friedman AM. Timing and Risk Factors of Postpartum Stroke. Obstet Gynecol 2018;131:70-8.

6. Hammer ES, Cipolla MJ. Cerebrovascular Dysfunction in Preeclamptic Pregnancies. Curr Hypertens Rep 2015;17:64.

7. Szecsi PB, Jørgensen M, Klajnbard A, Andersen MR, Colov NP, Stender S. Haemostatic reference intervals in pregnancy. Thrombosis \& Haemostasis 2010;103:718-27.

8. McLean KC, Bernstein IM, Brummel-Ziedins KE. Tissue factor-dependent thrombin generation across pregnancy. Am J Obstet Gynecol 2012;207:135.e1-6.

9. Cervera R, Serrano R, Pons-Estel GJ, Ceberio-Hualde L, Shoenfeld Y, de Ramón E, Buonaiuto V, Jacobsen S, Zeher MM, Tarr T, Tincani A, Taglietti M, Theodossiades G, Nomikou E, Galeazzi M, Bellisai F, Meroni PL, Derksen RH, de Groot PG, Baleva M, Mosca M, Bombardieri S, Houssiau F, Gris JC, Quéré I, Hachulla E, Vasconcelos C, Fernández-Nebro A, Haro M, Amoura Z, Miyara M, Tektonidou M, Espinosa G, Bertolaccini ML, Khamashta MA; Euro-Phospholipid Project Group (European Forum on Antiphospholipid Antibodies). Morbidity and mortality in the antiphospholipid syndrome during a 10 -year period: a multicentre prospective study of 1000 patients. Ann Rheum Dis 2015;74:1011-8.

10. West CA, Sasser JM, Baylis C. The enigma of continual plasma volume expansion in pregnancy: critical role of the renin-angiotensin-aldosterone system. Am J Physiol Renal Physiol 2016;311:F1125-34.
11. Rantanen K, Tatlisumak T. Stroke in women - oral contraception, pregnancy, and hormone replacement therapy. Curr Vasc Pharmacol 2013;11:58-73.

12. Pařízek A, Koucký M, Dušková M. Progesterone, inflammation and preterm labor. J Steroid Biochem Mol Biol 2014;139:159-65.

13. Grear KE, Bushnell CD. Stroke and Pregnancy: Clinical Presentation, Evaluation, Treatment, and Epidemiology. Clin Obstet Gynecol 2013;56:350-9.

14. Cipolla MJ. Cerebrovascular function in pregnancy and eclampsia. Hypertension 2007;50:14-24.

15. Sánchez-Aranguren LC, Prada CE, Riaño-Medina CE, Lopez M. Endothelial dysfunction and preeclampsia: role of oxidative stress. Front Physiol 2014;5:372.

16. Jones-Muhammad M, Warrington JP. Cerebral Blood Flow Regulation in Pregnancy, Hypertension, and Hypertensive Disorders of Pregnancy. Brain Sci 2019;9:224.

17. Skilton MR, Bonnet F, Begg LM, Juonala M, Kähönen M, Lehtimäki T, Viikari JS, Raitakari OT. Childbearing, child-rearing, cardiovascular risk factors, and progression of carotid intima-media thickness: the Cardiovascular Risk in Young Finns study. Stroke 2010;41:1332-7.

18. Miller EC, Yaghi S, Boehme AK, Willey JZ, Elkind MS, Marshall RS. Mechanisms and outcomes of stroke during pregnancy and the postpartum period: A cross-sectional study. Neurol Clin Pract 2016;6:29-39.

19. Butalia S, Audibert F, Côté AM, Firoz T, Logan AG, Magee LA, Mundle W, Rey E, Rabi DM, Daskalopoulou SS, Nerenberg KA; Hypertension Canada. Hypertension Canada's 2018 Guidelines for the Management of Hypertension in Pregnancy. Can J Cardiol 2018;34:526-31.

20. Sharshar T, Lamy C, Mas J. Incidence and causes of strokes associated with pregnancy and puerperium. A study in public hospitals of Ile de France. Stroke in Pregnancy Study Group. Stroke 1995;26:930-6.

21. Hacein-Bey L, Varelas PN, Ulmer JL, Mark LP, Raghavan K, Provenzale JM. Imaging of Cerebrovascular Disease in Pregnancy and the Puerperium. AJR Am J Roentgenol 2016;206:26-38.

22. Ladhani NNN, Swartz RH, Foley N, Nerenberg K, Smith EE, Gubitz G, Dowlatshahi D, Potts J, Ray JG, Barrett J, Bushnell C, Bal S, Chan WS, Chari R, El Amrani M, Gandhi S, Hill MD, James A, Jeerakathil T, Jin A, Kirton A, Lanthier S, Lausman A, Leffert LR, Mandzia J, Menon B, Pikula A, Poppe A, Saposnik G, Sharma M, Bhogal S, Smitko E, Lindsay MP. Canadian Stroke Best Practice Consensus Statement: Acute Stroke Management during 
pregnancy. Int J Stroke 2018;13:743-58.

23. Blythe R, Ismail A, Naqvi A. Mechanical Thrombectomy for Acute Ischemic Stroke in Pregnancy. J Stroke Cerebrovasc Dis 2019;28:e75-6.

24. Pacheco LD, Hankins GDV, Saad AF, Saade GR. Acute Management of Ischemic Stroke During Pregnancy. Obstet Gynecol 2019;133:933-9.

25. Tang CH, Wu CS, Lee TH, Hung ST, Yang CY, Lee CH, Chu PH. Preeclampsia-eclampsia and the risk of stroke among peripartum in Taiwan. Stroke 2009;40:1162-8.

26. Ray JG, Vermeulen MJ, Bharatha A, Montanera WJ, Park AL. Association Between MRI Exposure During Pregnancy and Fetal and Childhood Outcomes. JAMA 2016;316:952.

27. Wintermark M, Sanelli PC, Albers GW, Bello J, Derdeyn C, Hetts SW, Johnson MH, Kidwell C, Lev MH, Liebeskind DS, Rowley H, Schaefer PW, Sunshine JL, Zaharchuk G, Meltzer CC. Imaging Recommendations for Acute Stroke and Transient Ischemic Attack Patients: A Joint Statement by the American Society of Neuroradiology, the American College of Radiology, and the Society of NeuroInterventional Surgery. AJNR Am J Neuroradiol 2013;34:E117-27.

28. Haber MA, Diego N. Imaging neurological emergencies in pregnancy and puerperium. Emerg Radiol 2018;25:673-84.

29. Jaigobin C, Silver FL. Stroke and pregnancy. Stroke 2000;31:2948-51.

30. Dias MS, Sekhar LN. Intracranial hemorrhage from aneurysms and arteriovenous malformations during pregnancy and the puerperium. Neurosurgery 1990;27:855-65; discussion 865-6.

31. Salonen Ros H, Lichtenstein P, Bellocco R, Petersson $\mathrm{G}$, Cnattingius S. Increased risks of circulatory diseases in late pregnancy and puerperium. Epidemiology 2001;12:456-60.

32. Mas JL, Lamy C. Stroke in pregnancy and the puerperium. J Neurol 1998;245:305-13.

33. Zak IT, Dulai HS, Kish KK. Imaging of neurologic disorders associated with pregnancy and postpartum period. Radiographics 2007;27:95-108.

34. Stoodley MA, Macdonald RL, Weir BK. Pregnancy and intracranial aneurysms. Neurosurg Clin N Am 1998;9:549-56.

35. Chu W, Hua W. Transesophageal Echocardiography in Cardiogenic Embolic Cerebral Infarction. Pak J Med Sci 2018;34:58-61.

36. Kotsenas AL, Roth TC, Hershey BL, Yi JK. Imaging neurologic complications of pregnancy and the puerperium. Acad Radiol 1999;6:243-52.

37. Bousser MG, Ferro JM. Cerebral venous thrombosis: an update. Lancet Neurol 2007;6:162-70.

38. Saposnik G, Barinagarrementeria F, Brown RD Jr, Bushnell CD, Cucchiara B, Cushman M, deVeber G, Ferro JM, Tsai FY; American Heart Association Stroke Council and the Council on Epidemiology and Prevention. Diagnosis and Management of Cerebral Venous Thrombosis: A Statement for Healthcare Professionals From the American Heart Association/American Stroke Association. Stroke 2011;42:1158-92.

39. Ferro JM, Canhão P, Stam J, Bousser MG, Barinagarrementeria F; ISCVT Investigators. Prognosis of cerebral vein and dural sinus thrombosis: results of the International Study on Cerebral Vein and Dural Sinus Thrombosis (ISCVT). Stroke 2004;35:664-70.

40. Stam J. Thrombosis of the cerebral veins and sinuses. N Engl J Med 2005;352:1791-8.

41. Aguiar de Sousa D, Canhão P, Ferro JM. Safety of pregnancy after cerebral venous thrombosis: systematic review update. J Neurol 2018;265:211-2.

42. Ducreux D, Oppenheim C, Vandamme X, Dormont D, Samson Y, Rancurel G, Cosnard G, Marsault C. Diffusionweighted imaging patterns of brain damage associated with cerebral venous thrombosis. AJNR Am J Neuroradiol 2001;22:261-8.

43. Rizzo L, Crasto SG, Rudà R, Gallo G, Tola E, Garabello D, De Lucchi R. Cerebral venous thrombosis: role of CT, MRI and MRA in the emergency setting. Radiol Med 2010;115:313-25.

44. Ferro JM, Bousser MG, Canhão P, Coutinho JM, Crassard I, Dentali F, di Minno M, Maino A, Martinelli I, Masuhr F, Aguiar de Sousa D, Stam J; European Stroke Organization. European Stroke Organization guideline for the diagnosis and treatment of cerebral venous thrombosis - endorsed by the European Academy of Neurology. Eur J Neurol 2017;24:1203-13.

45. Leach JL, Fortuna RB, Jones BV, Gaskill-Shipley MF. Imaging of Cerebral Venous Thrombosis: Current Techniques, Spectrum of Findings, and Diagnostic Pitfalls. Radiographics 2006;26 Suppl 1:S19-41; discussion S42-3.

46. Aguiar de Sousa D, Canhão P, Crassard I, Coutinho J, Arauz A, Conforto A, Béjot Y, Giroud M, Ferro JM; ISCVT-2-PREGNANCY Investigators. Safety of Pregnancy After Cerebral Venous Thrombosis: Results of the ISCVT (International Study on Cerebral Vein and Dural Sinus Thrombosis)-2 PREGNANCY Study. Stroke 
2017;48:3130-3.

47. Idbaih A, Boukobza M, Crassard I, Porcher R, Bousser MG, Chabriat H. MRI of Clot in Cerebral Venous Thrombosis: High Diagnostic Value of SusceptibilityWeighted Images. Stroke 2006;37:991-5.

48. Provenzale JM, Kranz PG. Dural Sinus Thrombosis: Sources of Error in Image Interpretation. AJR Am J Roentgenol 2011;196:23-31.

49. Linn J, Ertl-Wagner B, Seelos KC, Strupp M, Reiser M, Brückmann H, Brüning R. Diagnostic value of multidetector-row CT angiography in the evaluation of thrombosis of the cerebral venous sinuses. AJNR Am J Neuroradiol 2007;28:946-52.

50. Fischer M, Schmutzhard E. Neuroimaging in posterior reversible encephalopathy syndrome. J Neurol 2017;264:1608-16.

51. Edlow JA, Caplan LR, O'Brien K, Tibbles CD. Diagnosis of acute neurological emergencies in pregnant and postpartum women. Lancet Neurol 2013;12:175-85.

52. McKinney AM, Short J, Truwit CL, McKinney ZJ, Kozak OS, SantaCruz KS, Teksam M. Posterior reversible encephalopathy syndrome: Incidence of atypical regions of involvement and imaging findings. AJR Am J Roentgenol 2007;189:904-12.

53. Liman TG, Bohner G, Heuschmann PU, Endres M, Siebert E. The clinical and radiological spectrum of posterior reversible encephalopathy syndrome: the retrospective Berlin PRES study. J Neurol 2012;259:155-64.

54. Fugate JE, Claassen DO, Cloft HJ, Kallmes DF, Kozak OS, Rabinstein AA. Posterior Reversible Encephalopathy Syndrome: Associated Clinical and Radiologic Findings. Mayo Clin Proc 2010;85:427-32.

55. Lindå H, Heijne AV. A Case of Posterior Reversible Encephalopathy Syndrome Associated with Gilenya ${ }^{\circledR}$ (Fingolimod) Treatment for Multiple Sclerosis. Front Neurol 2015;6:39.

56. Jeon JS, Park SP, Seo JG. Posterior reversible encephalopathy syndrome due to hyponatremia. J Epilepsy Res 2014;4:31-3.

57. Benziada-Boudour A, Schmitt E, Kremer S, Foscolo S, Rivière AS, Tisserand M, Boudour A, Bracard S. Posterior reversible encephalopathy syndrome: a case of unusual diffusion-weighted MR images. J Neuroradiol 2009;36:102-5.

58. Hefzy HM, Bartynski WS, Boardman JF. Hemorrhage in posterior reversible encephalopathy syndrome: imaging and clinical features. AJNR Am J Neuroradiol
2009;30:1371-9.

59. Shankar J, Banfield J. Posterior Reversible Encephalopathy Syndrome: A Review. Can Assoc Radiol J 2017;68:147-53.

60. Sheikh HU, Mathew PG. Reversible Cerebral Vasoconstriction Syndrome: Updates and New Perspectives. Curr Pain Headache Rep 2014;18:414.

61. Miller TR, Shivashankar R, Mossa-Basha M, Gandhi D. Reversible Cerebral Vasoconstriction Syndrome, Part 1: Epidemiology, Pathogenesis, and Clinical Course. AJNR Am J Neuroradiol 2015;36:1392-9.

62. Singhal AB, Topcuoglu MA. Glucocorticoid-associated worsening in reversible cerebral vasoconstriction syndrome. Neurology 2017;88:228-36.

63. Ducros A, Boukobza M, Porcher R, Sarov M, Valade D, Bousser MG. The clinical and radiological spectrum of reversible cerebral vasoconstriction syndrome. A prospective series of 67 patients. Brain 2007;130:3091-101.

64. Chen SP, Wang SJ. Hyperintense vessels: An early MRI marker of reversible cerebral vasoconstriction syndrome? Cephalalgia 2014;34:1038-9.

65. Marder CP, Donohue MM, Weinstein JR, Fink KR. Multimodal Imaging of Reversible Cerebral Vasoconstriction Syndrome: A Series of 6 Cases. AJNR Am J Neuroradiol 2012;33:1403-10.

66. Hammad TA, Hajj-Ali RA. Primary Angiitis of the Central Nervous System and Reversible Cerebral Vasoconstriction Syndrome. Curr Atheroscler Rep 2013;15:346.

67. Chen SP, Fuh JL, Lirng JF, Wang SJ. Hyperintense vessels on flair imaging in reversible cerebral vasoconstriction syndrome. Cephalalgia 2012;32:271-8.

68. Ducros A. Reversible cerebral vasoconstriction syndrome. Lancet Neurol 2012;11:906-17.

69. Nouh A, Remke J, Ruland S. Ischemic Posterior Circulation Stroke: A Review of Anatomy, Clinical Presentations, Diagnosis, and Current Management. Front Neurol 2014;5:30.

70. Mossa-Basha M, Hwang WD, De Havenon A, Hippe D, Balu N, Becker KJ, Tirschwell DT, Hatsukami T, Anzai Y, Yuan C. Multicontrast High-Resolution Vessel Wall Magnetic Resonance Imaging and Its Value in Differentiating Intracranial Vasculopathic Processes. Stroke 2015;46:1567-73.

71. Chan WS, Rey E, Kent NE; VTE in Pregnancy Guideline Working Group, Chan WS, Kent NE, Rey E, Corbett T, David M, Douglas MJ, Gibson PS, Magee L, Rodger M, Smith RE; Society of Obstetricians and Gynecologists of Canada. Venous thromboembolism and antithrombotic therapy in pregnancy. J Obstet 
Gynaecol Can 2014;36:527-53.

72. Lappin JM, Darke S, Duflou J, Kaye S, Farrell M. Fatal Stroke in Pregnancy and the Puerperium. Stroke 2018;49:3050-3.

73. Zheng MZ, Yang QY, Lu XD, Hu SL, Chai C, Shen W, Chang BG, Wang ZY, Xia S. Middle cerebral artery thrombus susceptibility-weighted imaging mapping predicts prognosis. Quant Imaging Med Surg 2019;9:1556-65.

74. Chen CY, Li CW, Mak HKF, Lin MF, Chan WP. Combined native magnetic resonance angiography, flow-quantifying, and perfusion-imaging for impending second-stroke assessment. Quant Imaging Med Surg 2019;9:521-9.
Cite this article as: Wang N, Shen X, Zhang G, Gao B, Lerner A. Cerebrovascular disease in pregnancy and puerperium: perspectives from neuroradiologists. Quant Imaging Med Surg 2021;11(2):838-851. doi: 10.21037/qims-20830 